\title{
Geochemical Characteristics of an Ancient Nuclear Reactor "Oklo"
}

\author{
H. Hidaka* \\ Department of Earth and Planetary Systems Science, Hiroshima University, Higashi-Hiroshima 739-8526, \\ Japan
}

Received: November 6, 2006; In Final Form: April 12, 2007

The Oklo uranium deposit at the Republic of Gabon, central Africa, had partly functioned as natural fission reactors. Many elements of the Oklo reactor zones and the related samples show the variations in the isotopic composition caused by a combination of nuclear fission, neutron capture, and radioactive decay. Isotopic studies provide useful information to estimate reactor conditions and to understand behavior of radionuclides in geological media. In my recent work, in-situ $\mathrm{REE}, \mathrm{Pb}$, and $\mathrm{U}$ isotopic analyses of individual tiny minerals in and around reactor zones have been performed using a Sensitive High Resolution Ion Micro-Probe (SHRIMP). The data suggest the adsorption property of apatite in trapping fissiogenic LREE and Pu migrated from the reactor zone, and distribution of fissiogenic REE under oxidizing atmosphere.

\section{Introduction}

The Oklo uranium deposit at the Republic of Gabon, central Africa, had partly functioned as natural fission reactors. Large-scale fission chain reactions spontaneously occurred at 16 separate areas in the Oklo deposit, so-called "reactor zones (hereafter RZs)", two billion years ago, and sustained for 24,000 to 200,000 years. Two more RZs have been identified at the Okelobondo and Bangombé uranium deposits close to Oklo. Figure 1(a) shows a map of the Oklo and Okélobondo uranium deposits.

Many elements of the Oklo RZs and the related samples show the variations in the isotopic composition caused by a combination of nuclear fission, neutron capture, and radioactive decay. Isotopic studies provide useful information to estimate reactor conditions and to understand behavior of radionuclides in geological media. ${ }^{1,2}$ The data are also of value in particle physics to examine time-variations of fundamental physical constants. ${ }^{3}$

Most of previous isotopic analyses for the Oklo studies were based on bulk analysis of the rock samples with chemical separation for individual elements. As the first stage of the Oklo study, retentivities of the most of the fissiogenic isotopes such as rare earth elements (REE), platinoid elements, and alkaline elements in the Oklo reactors were quantitatively determined from the isotopic data of the bulk analyses using thermal ionization mass spectrometry (TIMS) and inductively coupled plasma mass spectrometry (ICP-MS). Although the bulk analyses have provided precise isotopic data, the results indicate average information in the samples.

It is known that some kinds of fission products are heterogeneously distributed in uranium matrices, even if they have (a)

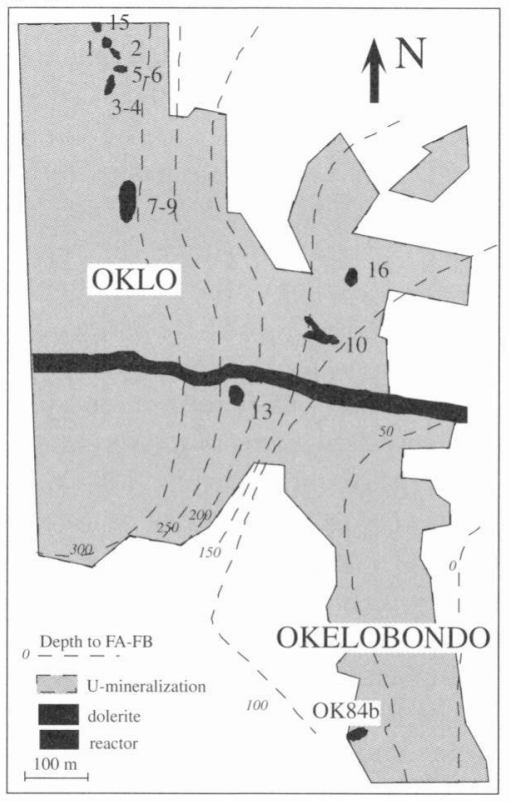

(b)

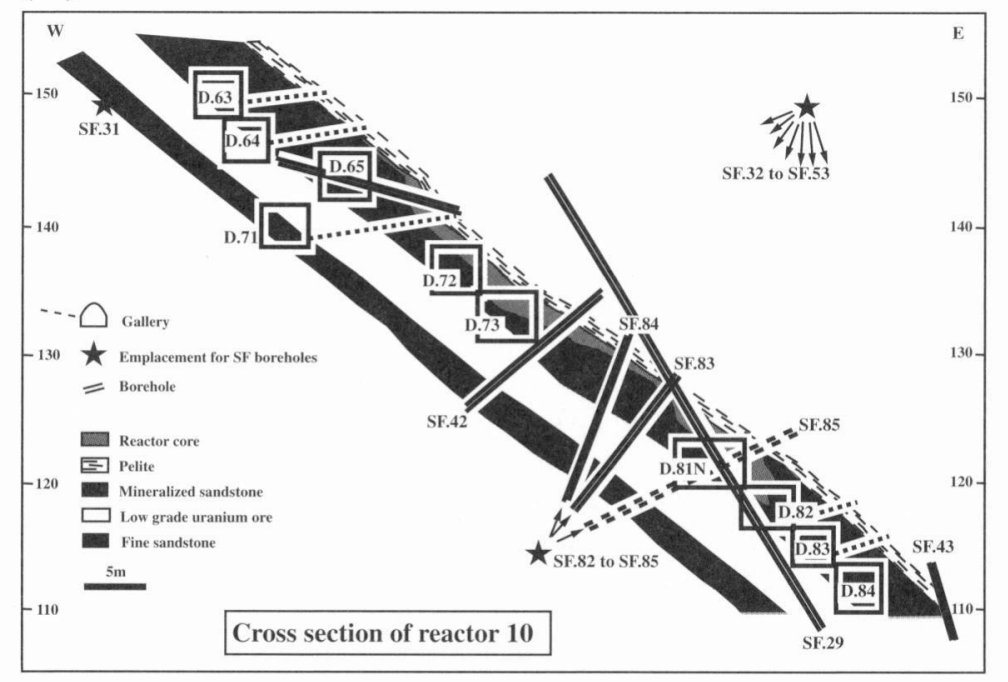

Figure 1. (a) A map of the Oklo-Okélobondo uranium deposits, Republic of Gabon. (b) A cross section of RZ 10. The sample used in this study was collected from one of drifts D81N that could be accessed to RZ 10.

*Corresponding author. E-mail: hidaka@hiroshima-u.ac.jp. Fax: $+81-82-424-7464$. 


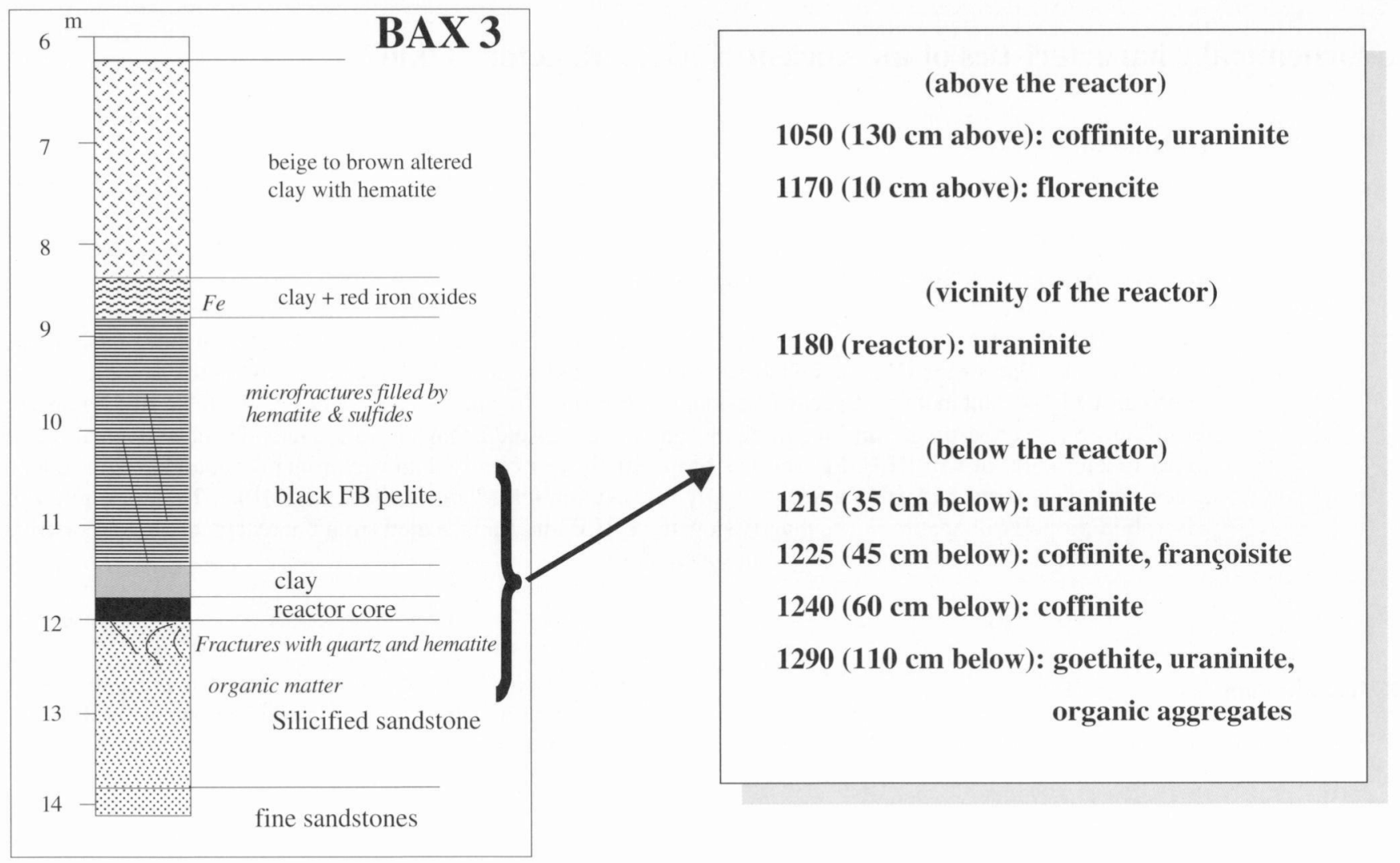

Figure 2. Petrologic type of stratigraphic section of the BAX3 drilling-core. Samples used in this study were collected from 1050, 1190,1215 , 1225,1240 , and $1290 \mathrm{~cm}$ in depth. The core of the reactor is at a depth of 1175 to $1180 \mathrm{~cm}$. Specific minerals found in the individual sections are described in the right column of the figure.

retained well in the reactor. In addition, even fission products having chemically good affinity with uranium might have partly remobilized out of the reactor in association with dissolution of reactor uraninite due to late weathering. From the mineralogical observation using scanning electron microscope (SEM) and transmitted electron microscope (TEM), partial dissolution of uraninite and recrystallization of uranium minerals in and around the RZs were confirmed. Therefore, for better understanding the migration mechanism of fission products out of the RZs, it is essential to perform microscopic isotopic observation on the Oklo samples. In-situ isotopic observation with secondary ion mass spectrometry (SIMS) has been widely used even in the field of geology and geochemistry. Secondarily formed minerals bearing fissiogenic products were found in peripheral rocks around the RZs. ${ }^{4-6}$ Instrumental development of micro-region analyses by SIMS offers great advantages in determining the migration and incorporation processes of fission products into specific minerals in and around natural fission reactors at Oklo and Bangombé. In my recent work, in-situ isotopic analyses of individual tiny minerals in and around reactor zones have been performed using a Sensitive High Resolution Ion Micro-Probe (SHRIMP).

The aim of this paper is to summarize the recent studies of natural reactors. This paper consists of two parts. Sections 2 and 3 review the current topics of geochemical behavior of fissiogenic isotopes migrated from the natural reactors on the basis of my isotopic studies. Section 4 reviews the applications of isotopic data to other research fields in connection with radioactive waste containment and particle physics.

\section{Analytical Method}

2.1. Geological background of samples. One of the samples, D81-13, was collected from the Oklo RZ 10. RZ 10 is in the mine around $310 \mathrm{~m}$ depth, and the most preserved from geological weathering and alteration. D $81 \mathrm{~N}$ is one of five drifts to be accessed to RZ 10. Figure 1(b) shows a cross section of RZ 10. D81-13 was collected from a part of the boundary layer between RZ 10 and sandstone layer just beneath the RZ, and contains high-grade uraninite and massive apatite concretions. The sample was used for $\mathrm{U}$ isotopic analyses for evidence of ${ }^{239} \mathrm{Pu}$ adsorption.

A series of samples BAX3.1050 to BAX.1290 were collected from one of drilling-cores, BAX3 at the Bangombé site. ${ }^{8}$ More than twenty boreholes were drilled to investigate the geological setting of the Bangombé RZ, but only three boreholes (BA145, $\mathrm{BAX} 3$, and BAX8) could intersect the RZ. The samples BAX3.1215, 1225, 1240, and 1290 are sandstones beneath the reactor. The samples BAX3.1190 and 1050 are clay and black shale layers, respectively, taken from above the reactor. Petrologic type of stratigraphic section of the BAX3 drillingcore is shown in Figure 2. The Bangombé RZ is located at $11.80 \mathrm{~m}$ depth within the groundwater discharge area, and is affected by weathering and chemical reactions due to the groundwater flow. This suggests that a part of the fission products was released from the reactor and distributed in the wall rocks. Migration behavior of fissiogenic REE can be discussed from the distribution profile of isotopic variations with depth. Several kinds of secondarily formed uranium minerals have been found in peripheral rocks of the RZ.

The sample SD37.10 was taken from the sandstone layer near RZ 13. RZ 13 is located close to a dolerite dyke which intruded the strata 860 million years ago. The sandstone includes a number of calcite veins possibly caused by hydrothermal activity due to the dolerite intrusion. The sample was used for $\mathrm{Pb}$ isotopic study for evidence of ${ }^{226} \mathrm{Ra}$ adsorption. Several tiny illite grains sized about $100 \mu \mathrm{m}$ were found in fine calcite veins with 0.1 to $2 \mathrm{~mm}$ width in quartz matrix texture

For comparison of the isotopic data between fissiogenic and non-fissiogenic components, standard materials without fissiogenic component are required as standard materials. In this study, the Faraday Mine uraninite, PRAP apatite, and NIST610 
TABLE 1: ${ }^{235} \mathrm{U} /{ }^{238} \mathrm{U}$ isotopic ratios in apatite and uraninite of D81-13 (RZ 10) ${ }^{7}$

\begin{tabular}{lc}
\hline Sample & ${ }^{235} \mathrm{U} /{ }^{238} \mathrm{U}$ \\
\hline Apatite-1 & $0.00730 \pm 0.00011$ \\
Apatite-2 & $0.01303 \pm 0.00102$ \\
Apatite-3 & $0.00944 \pm 0.00083$ \\
Apatite-4 & $0.01707 \pm 0.00057$ \\
Apatite-5 & $0.01346 \pm 0.00044$ \\
\hline Standard apatite* & $0.00727 \pm 0.00006$ \\
\hline Uraninite-1 & $0.00663 \pm 0.00002$ \\
Uraninite-2 & $0.00659 \pm 0.00002$ \\
Uraninite-3 & $0.00666 \pm 0.00002$ \\
Uraninite-4 & $0.00661 \pm 0.00002$ \\
\hline Standard uraninite* & $0.00725 \pm 0.00003$ \\
\hline
\end{tabular}

Analytical errors indicate $1 \sigma$ of the mean.

*PRAP apatite ${ }^{7}$ and Faraday mine uraninite ${ }^{7}$ were used as standard minerals for ${ }^{235} \mathrm{U} /{ }^{238} \mathrm{U}$ isotopic analyses.

\section{standard glass were used.,}

2.2. Preparation of polished sections. Each sample was cut and mounted in an epoxy resin disk of 1-inch diameter. The surface of the sample was polished with $1 / 4 \mu \mathrm{m}$ diamond paste. Before in-situ isotopic analyses, mineral observations of all polished section samples were done by an optical microscope and an electron probe micro-analyzer (JEOL XA-8200). In particular, several kinds of phosphate minerals such as florencite $\left((\mathrm{REE}) \mathrm{Al}_{3}\left(\mathrm{PO}_{4}\right)_{2}(\mathrm{OH})_{6}\right)$, françoisite $\left((\mathrm{REE})\left(\mathrm{UO}_{2}\right)_{3} \mathrm{O}(\mathrm{O}\right.$ $\left.\mathrm{H})\left(\mathrm{PO}_{4}\right)_{6} \mathrm{H}_{2} \mathrm{O}\right)$ and $\mathrm{P}$-enriched coffinite $\left(\mathrm{USiO}_{4}\right)$ were identified from the BAX3 drill-core samples (see Figure 2).

2.3. In-situ isotopic analysis by SHRIMP. Isotopic analyses of lighter REE (LREE) in micro-region using SIMS have been effectively used to discuss the migration processes of fissiogenic isotopes into U- and REE-bearing minerals, because LREE are highly produced by $\mathrm{U}$ fission in the natural reactors. Here I focus on $\mathrm{Pb}, \mathrm{U}$, and REE isotopic analyses of the individual minerals by SHRIMP.

SHRIMP was originally designed for the analysis of geological materials and constructed at Australian National University. Physically large mass analyzer consists of a $72.5^{\circ}$ sector magnet with $100 \mathrm{~cm}$ turning radius and a cylindrical $85^{\circ}$ electrostatic analyzer with $127.2 \mathrm{~cm}$ radius, which allows for high mass resolution. The instrument used in this study, SHRIMP II was installed at Hiroshima University in 1997. 2 to $2.5 \mathrm{nA}$ of $\mathrm{O}_{2}{ }^{-}$primary ion beam focused on a $20 \mu$ m diameter spot was used for the analysis in this study.

For $\mathrm{Pb}$ and $\mathrm{U}$ isotopic analyses, the masses of ${ }^{204} \mathrm{~Pb},{ }^{206} \mathrm{~Pb}$, ${ }^{208} \mathrm{~Pb},{ }^{235} \mathrm{U}$, and ${ }^{238} \mathrm{U}$ were scanned with a mass resolution about $5800(M / \Delta M$ at $1 \%$ of the peak height). On the other hand, the mass resolution was set to higher than 9000 to avoid isobaric interferences of oxide and some unknown species onto atomic REE ion peak. The masses of ${ }^{140} \mathrm{Ce},{ }^{142} \mathrm{Ce}+{ }^{142} \mathrm{Nd},{ }^{143} \mathrm{Nd},{ }^{144} \mathrm{Sm}$ $+{ }^{144} \mathrm{Nd},{ }^{145} \mathrm{Nd},{ }^{146} \mathrm{Nd},{ }^{147} \mathrm{Sm},{ }^{148} \mathrm{Nd},{ }^{149} \mathrm{Sm},{ }^{150} \mathrm{Nd}+{ }^{150} \mathrm{Sm},{ }^{151} \mathrm{Eu}$, ${ }^{152} \mathrm{Sm}$, and ${ }^{153} \mathrm{Eu}$ were scanned for LREE isotopic analyses. ${ }^{142} \mathrm{Ce},{ }^{144} \mathrm{Sm}$, and ${ }^{150} \mathrm{Sm}$ isotopic abundances can be obtained from subtraction of ${ }^{142} \mathrm{Nd},{ }^{144} \mathrm{Nd}$, and ${ }^{150} \mathrm{Nd}$ isotopic abundances, respectively, because isotopic abundances of ${ }^{142} \mathrm{Nd},{ }^{144} \mathrm{Nd}$, and ${ }^{150} \mathrm{Nd}$ can be expected from those of ${ }^{145} \mathrm{Nd},{ }^{146} \mathrm{Nd}$, and ${ }^{148} \mathrm{Nd} .{ }^{8}$

\section{Discussion}

3.1. $U$ isotopic ratios of apatite. In the Oklo samples, ${ }^{235} \mathrm{U}$ depletion $\left({ }^{235} \mathrm{U} /{ }^{238} \mathrm{U}<0.00725\right)$ has been generally found, because ${ }^{235} \mathrm{U}$ was consumed by fission reactions in the reactors. Depleted U migrated from the reactor to peripheral rocks in association with dissolution of reactor $\mathrm{U}$ provides $\mathrm{U}$ isotopic anomalies even in wall rocks of the reactor. However, in an extremely rare case, ${ }^{235} \mathrm{U}$ excess $\left({ }^{235} \mathrm{U} /{ }^{238} \mathrm{U}>0.00725\right)$ was reported from the Oklo samples. ${ }^{9,10}$ The ${ }^{235} \mathrm{U}$ excess is interpreted as a result of selective uptake of ${ }^{239} \mathrm{Pu}$ in association with chemical differentiation between $\mathrm{U}$ and $\mathrm{Pu} .{ }^{239} \mathrm{Pu}$ with a halflife of $2.4 \times 10^{4}$ years was produced from the neutron capture of ${ }^{238} \mathrm{U}$ in the RZs, and decays to ${ }^{235} \mathrm{U}$.

${ }^{235} \mathrm{U} /{ }^{238} \mathrm{U}$ isotopic ratios of apatite and uraninite in D81-13 are shown in Table 1. Although the data of apatite include large analytical errors because of low U content, significant ${ }^{235} \mathrm{U}$ excesses $\left({ }^{235} \mathrm{U} /{ }^{238} \mathrm{U}=0.00944\right.$ to 0.01707$)$ are observed from four of five analytical spots in the apatite. On the other hand, the isotopic data of uraninite coexisting with apatite in the sample show depletion of ${ }^{235} U\left({ }^{235} U /{ }^{238} U=0.00659\right.$ to 0.00666 ), which indicates that the uraninite is a reactor material that experienced fission reaction. The ${ }^{235} \mathrm{U} /{ }^{238} \mathrm{U}$ ratios of apatite in this study are much higher than those previously reported in clay minerals from the sandstone layer around RZ 10 and apatite from RZ 16. ${ }^{9,10}$ This suggests heterogeneous distribution of ${ }^{239} \mathrm{Pu}$ out of the reactors.

$\mathrm{REE}$ data also support the $\mathrm{Pu}$ migration in apatite. High amount of fissiogenic $\mathrm{Nd}$ was also observed in the apatite grain. ${ }^{7}$ Since one of REE, Nd has been often used as an analogue of $\mathrm{Pu}$ in geochemical fields, ${ }^{11,12}$ it is reasonable that fissiogenic $\mathrm{Nd}$ and nucleogenic ${ }^{239} \mathrm{Pu}$ were incorporated into the apatite grain. The petrologic texture of the D81-13 sample shows that a part of uraninite grains were recrystallized, suggesting that the sample was subjected to the interaction with thermal fluid that flowed after operation of the reactor. Chemical fractionation between $\mathrm{U}$ and $\mathrm{Pu}$ might have occurred in association with the partial dissolution of uraninite.

3.2. Distribution of fissiogenic LREE isotopes with depth. Fission and neutron capture reactions are main reactions that cause the significant isotopic anomalies of the elements in a reactor. ${ }^{140} \mathrm{Ce},{ }^{142} \mathrm{Ce},{ }^{143} \mathrm{Nd},{ }^{146} \mathrm{Nd},{ }^{147} \mathrm{Sm},{ }^{149} \mathrm{Sm},{ }^{151} \mathrm{Eu}$, and ${ }^{153} \mathrm{Eu}$ of the samples used in this study include fissiogenic component as well as non-fissiogenic component, because they are not shielded from $\beta$ decay. Considering the fission product yields of individual isotopes, ${ }^{140} \mathrm{Ce} /{ }^{142} \mathrm{Ce}$ isotopic ratios of the samples are expected to be lower than those of non-fissiogenic standard sample. On the other hand, ${ }^{143} \mathrm{Nd} /{ }^{146} \mathrm{Nd}$ and ${ }^{151} \mathrm{Eu} /{ }^{153} \mathrm{Eu}$ isotopic ratios of the samples are expected to be higher than those of standard sample. The ${ }^{149} \mathrm{Sm} /{ }^{147} \mathrm{Sm}$ ratios are expected to be lower than that of standard materials because of extremely large neutron capture cross section of ${ }^{149} \mathrm{Sm}$. Stille et al ${ }^{13}$ reported the isotopic variations of ${ }^{143} \mathrm{Nd} /{ }^{146} \mathrm{Nd}$ and ${ }^{149} \mathrm{Sm} /{ }^{147} \mathrm{Sm}$ in the BAX8 drill core that is another drill-core cross-cutting the reactor, and concluded that fissiogenic REE were not detected at a larger distance than $3 \mathrm{~m}$ from the reactor. Therefore, the attention for redistribution of REE in this study should be paid to the region within $1 \mathrm{~m}$ above or beneath the reactor.

The most important difference in mineralogy between BAX3 and other drill-cores is the occurrence of uraninite, coffinite, and phosphatian U-minerals. The coffinite and phosphatian minerals are considered to be formed by supergene weathering. ${ }^{13}$ As shown in Figure 2, several kinds of secondarily formed U- and REE bearing minerals were found near the RZ..$^{8,14}$ Isotopic data of ${ }^{140} \mathrm{Ce} /{ }^{142} \mathrm{Ce},{ }^{143} \mathrm{Nd} /{ }^{146} \mathrm{Nd}$, and ${ }^{149} \mathrm{Sm} /{ }^{147} \mathrm{Sm}$ show clear evidence of incorporation of fissiogenic isotopes in these minerals, while such evidence is not clearly identified from the ${ }^{151} \mathrm{Eu} /{ }^{153} \mathrm{Eu}$ ratios because of low fission product yields of ${ }^{151} \mathrm{Eu}$ and ${ }^{153} \mathrm{Eu}$. The ${ }^{140} \mathrm{Ce} /{ }^{142} \mathrm{Ce},{ }^{143} \mathrm{Nd} /{ }^{146} \mathrm{Nd}$, and ${ }^{149} \mathrm{Sm} /{ }^{147} \mathrm{Sm}$ isotopic data vary with the location distance from the RZ. As one of example, Figure 3 shows depth-dependent variations of ${ }^{140} \mathrm{Ce} /{ }^{142} \mathrm{Ce}$ in the BAX3 drill core ${ }^{8,14}$ The reactor core mainly consisting of fissiogenic isotopes has the lowest ${ }^{140} \mathrm{Ce} /{ }^{142} \mathrm{Ce}$ value of 2.209 . The ratios gradually increase 


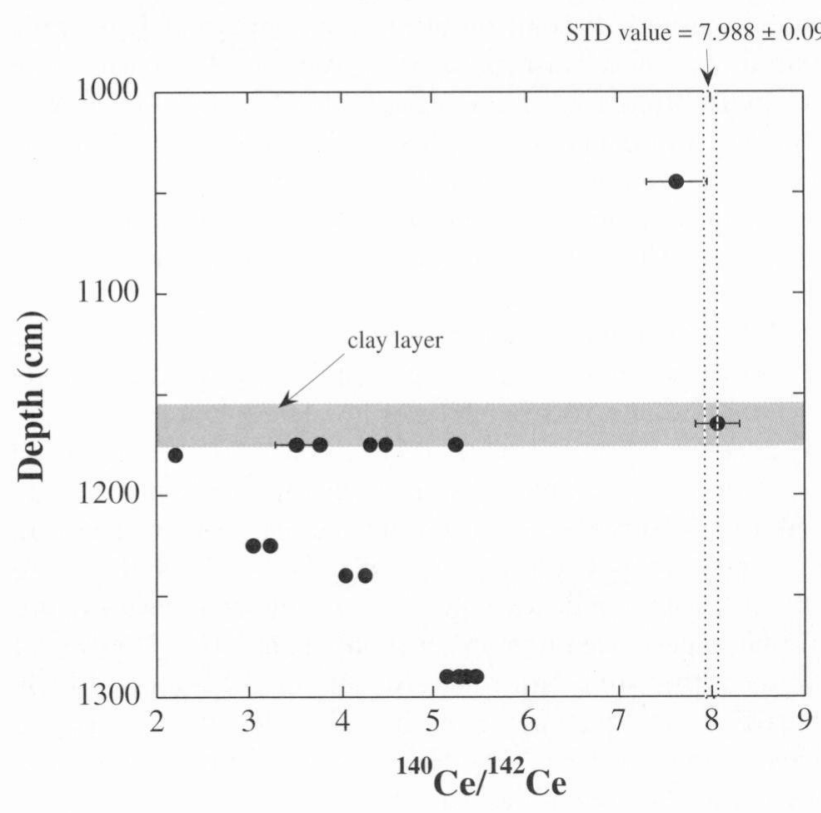

Figure 3. Variation of ${ }^{140} \mathrm{Ce} /{ }^{142} \mathrm{Ce}$ isotopic ratios with depth in the BAX3 drilling-core. Shaded zone in the figure corresponds to a clay layer just above the reactor. Terrestrial standard value of ${ }^{140} \mathrm{Ce} /{ }^{142} \mathrm{Ce}$ isotopic ratio is $7.988 \pm 0.098$. Error bars of individual data points indicate $1 \sigma$ of the means.

with the distance from the reactor in the sandstone layer (1215 to 1290 ), which reveals that supergene weathering led to the redistribution of fissiogenic REE. However, the variation of ${ }^{140} \mathrm{Ce} /{ }^{142} \mathrm{Ce}$ ratios above the reactor $(1050$ to 1180$)$ shows a different trend from those under the reactor. In particular, the Ce isotopic variation is rather sharp in the clay layer (depths between 1160 and $1180 \mathrm{~cm}$ in Figure 3), which indicates that migration of fissiogenic Ce was limited. The variations of ${ }^{143} \mathrm{Nd} /{ }^{146} \mathrm{Nd}$ and ${ }^{149} \mathrm{Sm} /{ }^{147} \mathrm{Sm}$ ratios with depth also show the similar trend. ${ }^{14}$ Most of fissiogenic Ce, Nd, and Sm were probably adsorbed by clays. This result provides a simple illustration of the performance of a clay barrier in the uptake of fission products by adsorption onto clays and incorporation in secondarily formed U-bearing minerals.

3.3. $\mathrm{Pb}$ isotopic ratios of illite. Radium has no stable isotopes. ${ }^{226} \mathrm{Ra}$ having the longest half-life $\left(T_{1 / 2}=1600 \mathrm{y}\right)$ among radium radioisotopes exists as a radioactive precursor of final decay product from ${ }^{238} \mathrm{U}$ in nature, and finally decays to stable isotope ${ }^{206} \mathrm{~Pb}$. Long-lived nuclides such as ${ }^{226} \mathrm{Ra}$ may be fractionated from their parents in association with geochemical events in the terrestrial environments. It is of particular inter- est to understand the geochemical behaviors of Ra from the viewpoint of long-term repository safety of radionuclear waste.

$\mathrm{Pb}$ isotopic compositions of geological samples provide chronological information, if a radiochemical equilibrium is established between $\mathrm{U}$ and $\mathrm{Pb}$. The $\mathrm{Pb}$ isotopic ratios, ${ }^{207} \mathrm{~Pb} /{ }^{206} \mathrm{~Pb}$, in geological samples normally show over 0.04604 , because radiogenic ${ }^{207} \mathrm{~Pb}$ and ${ }^{206} \mathrm{~Pb}$ are decay products from ${ }^{235} \mathrm{U}\left(T_{1 / 2}=7.04 \times 10^{8} \mathrm{y}\right)$ and ${ }^{238} \mathrm{U}\left(T_{1 / 2}=4.47 \times 10^{9} \mathrm{y}\right)$, respectively. The sample SD37.10 used in this study mainly consists of quartz, and contains calcite veins and illite grains. The ${ }^{207} \mathrm{~Pb} /{ }^{206} \mathrm{~Pb}$ isotopic ratios of quartz, calcite, and illite in the sample are shown in Table 2. The $\mathrm{Pb}$ isotopic data of quartz and calcite in the sample provide the geochronological information corresponding to the formation of 2.15 billion year-old basement rocks and the occurrence of later hydrothermal activity in this region at 0.88 billion years, respectively. ${ }^{15}$ On the other hand, illite shows high enrichment of ${ }^{206} \mathrm{~Pb}$, which cannot be explained simply from normal $\mathrm{U}$ decays. ${ }^{15}$

In the case of the Oklo reactor samples, it is also possible to explain the low ${ }^{207} \mathrm{~Pb} /{ }^{206} \mathrm{~Pb}$ isotopic ratios as decay products from ${ }^{235} \mathrm{U}$-depleted reactor material. Although reactor zone 13 is a small reactor ( $6 \mathrm{~m}$ wide and $10 \mathrm{~m}$ long), the vicinity of the reactor has a very high uranium content (up to 87 wt. $\% \mathrm{UO}_{2}$ ) with a high depletion of ${ }^{235} U\left({ }^{235} U /{ }^{238} U=0.0038\right)$ as the lowest value. ${ }^{16}$ Depleted U can indeed produce lower ${ }^{207} \mathrm{~Pb} /{ }^{206} \mathrm{~Pb}$ isotopic ratios, however, an extremely high depletion of ${ }^{235} \mathrm{U}$ $\left.{ }^{235} \mathrm{U} /{ }^{238} \mathrm{U}=0.00212\right)$ is required to produce the low ${ }^{207} \mathrm{~Pb} /{ }^{206} \mathrm{~Pb}$ ratios (the lowest value $=0.0146$ ) observed in the illite Therefore, it is impossible to explain the low ${ }^{207} \mathrm{~Pb} /{ }^{206} \mathrm{~Pb}$ ratios by the decay from depleted $\mathrm{U}$ even in the most depleted $\mathrm{U}$ region of the Oklo natural fission reactor. Moreover, $\mathrm{U}$ isotopic compositions in the illite show normal $\mathrm{U}$ isotopic compositions $\left({ }^{235} U /{ }^{238} U=0.00725\right)$ without depletion of ${ }^{235} \mathrm{U}$ within analytical uncertainties. Therefore, another reason is required to explain the low ${ }^{207} \mathrm{~Pb} /{ }^{206} \mathrm{~Pb}$ ratios in illite.

Chemical data also support that the low ${ }^{207} \mathrm{~Pb} /{ }^{206} \mathrm{~Pb}$ ratios were caused by selective adsorption of ${ }^{226} \mathrm{Ra}$. Ba has been often used as a chemical analogue of $\mathrm{Ra}^{17}$ Illite grains having low ${ }^{207} \mathrm{~Pb} /{ }^{206} \mathrm{~Pb}$ isotopic ratios also show a strong enrichment of $\mathrm{Ba}$. The Ba concentrations of the illite grains are a few hundreds to a few thousands times higher than those in calcite and quartz coexisting with illite in the sample SD $37.10 .{ }^{15}$ Considering that $\mathrm{Ba}$ has been used as a chemical tracer of ${ }^{226} \mathrm{Ra}$ because of the chemical similarities between $\mathrm{Ba}$ and $\mathrm{Ra}$, the extremely low ${ }^{207} \mathrm{~Pb} /{ }^{206} \mathrm{~Pb}$ ratios strongly suggest the selective adsorption of ${ }^{226} \mathrm{Ra}$ as a precursor of ${ }^{206} \mathrm{~Pb}$ in the illite grains.

TABLE 2: Pb isotopic ratios in quartz, calcite, and illite of SD37.10 (RZ 13) ${ }^{15}$

\begin{tabular}{|c|c|c|c|}
\hline Sample & ${ }^{204} \mathrm{~Pb} /{ }^{206} \mathrm{~Pb}$ & ${ }^{207} \mathrm{~Pb} /{ }^{206} \mathrm{~Pb}$ & ${ }^{208} \mathrm{~Pb} /{ }^{206} \mathrm{~Pb}$ \\
\hline Quartz-1 & $0.00171 \pm 0.00054$ & $0.120 \pm 0.019$ & $0.013 \pm 0.004$ \\
\hline Quartz-2 & $0.00298 \pm 0.00044$ & $0.169 \pm 0.004$ & $0.132 \pm 0.006$ \\
\hline Quartz-3 & $0.00043 \pm 0.00011$ & $0.149 \pm 0.030$ & $0.007 \pm 0.001$ \\
\hline Quartz-4 & $0.00150 \pm 0.00020$ & $0.148 \pm 0.007$ & $0.085 \pm 0.014$ \\
\hline Calcite-1 & $0.00029 \pm 0.00003$ & $0.1071 \pm 0.0019$ & $0.0137 \pm 0.0003$ \\
\hline Calcite-2 & $0.00027 \pm 0.00006$ & $0.1429 \pm 0.0011$ & $0.0115 \pm 0.0004$ \\
\hline Calcite-3 & $0.00078 \pm 0.00018$ & $0.0979 \pm 0.0007$ & $0.0328 \pm 0.0113$ \\
\hline Calcite-4 & $0.00199 \pm 0.00099$ & $0.1703 \pm 0.0072$ & $0.0388 \pm 0.0046$ \\
\hline Illite-1 & $0.000087 \pm 0.000007$ & $0.0146 \pm 0.0003$ & $0.00526 \pm 0.00019$ \\
\hline Illite-2 & $0.000080 \pm 0.000002$ & $0.0158 \pm 0.0001$ & $0.00439 \pm 0.00012$ \\
\hline Illite-3 & $0.000108 \pm 0.000006$ & $0.0171 \pm 0.0003$ & $0.00589 \pm 0.00012$ \\
\hline Illite-4 & $0.000131 \pm 0.000003$ & $0.0171 \pm 0.0001$ & $0.00602 \pm 0.00008$ \\
\hline
\end{tabular}

Analytical errors indicate $1 \sigma$ of the mean. 


\section{Other Applications}

Besides the geochemical studies of the migration behavior of fissiogenic isotopes, the isotopic data of RZs have relevance to other topics, geological repositories for the containment of radioactive waste and estimation of time-variation of fundamental constants.

4.1. Role of organic matters. Nagy et al. ${ }^{18,19}$ studied organic matters in and around the Oklo RZs, and found that solid bitumens contain highly condensed aromatic hydrocarbons. Furthermore, they pointed out an important role of the bitumens to efficiently constrain mobilization and redistribution of uranium and fission products. Liquid bitumen is considered to have been produced from organic matters by hydrothermal event during the reactor criticality, and soon became a solid to contain uraninite. Mossman et al..$^{20,21}$ reported the results of in-situ analyses of trace elements in the bitumens by a laser ablation ICP-MS to find enrichments of fission products. The various types of bitumen were distinguished by reflectance characteristics and $\delta^{13} \mathrm{C}$ values. The results from the LA-ICPMS analysis show that fissiogenic alkaline and alkaline earth elements have migrated from RZs either dissolved, or as fine particulate materials, in once liquid bitumen. This fact has interesting implications for the evaluation of long-term containment of radionuclides.

4.2. Particle physics. In Physics field, there are fundamental constants such as the speed of light $c$, the Dirac constant $\hbar$, the Newtonian gravitational constant $G$, the Coulomb coupling constant $\alpha=e^{2} /(4 \pi c \hbar)$, and the strong-interaction counterpart of the fine-structure constant $\alpha_{\mathrm{s}}=g^{2} /(4 \pi c \hbar)$. Dirac firstly suggested the time variation of one of fundamental constants, $G$, based on his own "Large-numbers Hypothesis". ${ }^{22}$ Several approaches have been attempted to set observational and experimental bounds on the time variation of fundamental constants. $^{23-25}$

In fact, there has been great interest by particle physicists in the constancy of the strong interaction coupling constant as a function of time. Shlyakhter ${ }^{26}$ exploited the calculation method of the bounds for $\alpha$ and $\alpha_{\mathrm{s}}$ from the isotopic variation of ${ }^{149} \mathrm{Sm}$ due to neutron capture reactions in an Oklo reactor. After 20 years interval from Shlyakhter's first report, ${ }^{26}$ there are several reports to estimate the upper bounds of the constants $\alpha$ and $\alpha$ s from the Oklo isotopic data. ${ }^{3,27,28}$ It is still disputable to mention the conclusive decision about the time-variation of the fundamental constants from the Oklo study, because there are some ambiguities for the estimation. However, it is quite remarkable that isotopic studies of the Oklo reactors are of relevance to particle physics.

\section{Conclusion}

Since the discovery of the first natural reactor at the Oklo uranium ore in 1972, a number of systematic isotopic studies have been performed to investigate the geochemical behavior of elements and to characterize the operating conditions of the natural reactors. In-situ isotopic analyses using a SHRIMP are effectively used to investigate the geochemical characteristics of fissiogenic and nucleogenic isotopes migrated from nuclear reactors in geosphere. Apatite and clay minerals found near RZs show a strong isotopic evidence of selective adsorption of $\mathrm{Pu}$ and $\mathrm{Ra}$, respectively. REE isotopic data of secondary $\mathrm{U}-$ and REE-bearing minerals provide the redistribution of fissiogenic REE due to supergene weathering. These results were firstly clarified using isotopic observations in micro- to submicro region of specific natural minerals. The isotopic studies provide insights on the mechanism of mobilization and retardation of radioisotopes in repository materials for radiowaste disposal. In addition, it is quite interesting that the isotopic data are also of value in particle physics to examine time-variations of fundamental physical constants.

Acknowledgement. The author would like to acknowledge F. Gauthier-Lafaye, K. Horie, and M. Kikuchi for many helpful discussions and experimental assistances. A part of this study was financially supported by a Grant-in-Aid for Scientific Research of Japan Society for the Promotion of Science (No. 17204051).

\section{References}

(1) F. Gauthier-Lafaye, P. Holliger, and P.-L. Blanc, Geochim. Cosmochim. Acta 60, 4831 (1996)

(2) H. Hidaka and P. Holliger, Geochim. Cosmochim. Acta 62, 89 (1998).

(3) Y. Fujii, A. Iwamoto, T. Fukahori, T. Ohnuki, M. Nakagawa, H. Hidaka, Y. Oura, and P. Möller, Nucl. Phys. B 573, 377 (2000).

(4) P. Holliger, CEA-DTA-CENG Technical Note DEM No. 01/92 (1992).

(5) J. Janeczek and R. C. Ewing, Am. Mineral. 81, 1263 (1996).

(6) J. Janeczek and R. C. Ewing, Mineral. Mag. 60, 665 (1996).

(7) K. Horie, H. Hidaka, and F. Gauthier-Lafaye, Geochim. Cosmochim. Acta 68, 115 (2004).

(8) H. Hidaka, J. Janeczek, F. N. Skomurski, R. C. Ewing, and F. Gauthier-Lafaye, Geochim. Cosmochim. Acta 69, 685 (2005).

(9) R. Bros, L. Turpin, F. Gauthier-Lafaye, P. Holliger, and P. Stille, Geochim. Cosmochim. Acta 57, 1351 (1993).

(10) R. Bros, J. Carpena, V. Sere, and A. Beltritti, Radiochim. Acta 74, 277 (1996).

(11) G. W. Lugmair and K. Marti, Earth Planet. Sci. Lett. 35, 273 (1977).

(12) N. A. Chapman and J. A. T. Smellie, Chem. Geol. 55, 167 (1986).

(13) P. Stille, F. Gauthier-Lafaye, K. A. Jensen, S. Salah, G. Bracke, R. C. Ewing, D. Louvat, and D. Million, Chem. Geol. 198, 289 (2003).

(14) M. Kikuchi, H. Hidaka, and K. Horie, Geochim. Cosmochim. Acta 70, A317 (2006).

(15) K. Horie, H. Hidaka, and F. Gauthier-Lafaye, Geochim. Cosmochim. Acta 67, A156 (2003).

(16) H. Hidaka, Radiochim. Acta 82, 327 (1998).

(17)B. L. Grütter, H. R. von Gunten, and E. Rössler, Radiochim. Acta 58/59, 259 (1992).

(18) B. Nagy, F. Gauthier-Lafaye, P. Holliger, D. J. Mossman, J. S. Leventhal, M. J. Rigali, and J. Parnell, Nature 354, 472 (1991)

(19) B. Nagy, F. Gauthier-Lafaye, P. Holliger, D. J. Mossman, J. S. Leventhal, and M. J. Rigali, Geology 21, 655 (1993).

(20) D. J. Mossman, F. Gauthier-Lafaye, and S. E. Jackson, Precambrian Res. 106, 135 (2001).

(21)D. J. Mossman, F. Gauthier-Lafaye, and S. E. Jackson, Precambrian Res. 137, 253 (2005).

(22) P. M. A. Dirac, Nature 139, 323 (1937).

(23) R. W. Hellings, P. J. Adams, J. D. Anderson, M. S. Keesey, E. L. Lau, E. M. Standish, V. M. Canuto, and I. Goldman, Phys. Rev. Lett. 51, 1609 (1983).

(24) A. Godone, C. Novero, P. Tavella, and K. Rahimullah, Phys. Rev. Lett. 71, 2364 (1993).

(25) J. K. Webb, V. V. Flambaum, C. W. Churchill, M. J. Drinkwater, and J. D. Barrow, Phys. Rev. Lett. 82, 884 (1999).

(26) A. I. Shlyakhter, Nature 264, 340 (1976).

(27) T. Damour and F. Dyson, Nucl. Phys. B 480, 37 (1996).

(28) S. K. Lamoreaux and R. Torgerson, Phys. Rev. D 69 , 121701 (2004). 